\title{
Mussel-Inspired Electro-Cross-Linking of Enzymes for the Development of Biosensors
}

\author{
Janwa El-Maiss, ${ }^{\dagger}$ Marco Cuccarese, ${ }^{\dagger,}$ Clément Maerten, ${ }^{\dagger}$ Paolo Lupattelli, ${ }^{\dagger,}$ Lucia Chiummiento, ${ }^{\ddagger}$ \\ Maria Funicello, ${ }^{\dagger}$ Pierre Schaaf, ${ }^{\dagger,}, \|, \perp, \#, \nabla_{\odot}$ Loï Jierry, ${ }^{\dagger, \S}$ and Fouzia Boulmedais ${ }^{*}, \dagger, \| \odot$ \\ ${ }^{\dagger}$ Université de Strasbourg, CNRS, Institut Charles Sadron UPR 22, 67034 Strasbourg, France \\ ${ }^{\ddagger}$ Dipartimento di Scienze, Università degli Studi della Basilicata, 85100 Potenza, Italy \\ ${ }^{\S}$ Ecole de Chimie, Polymères et Matériaux, Université de Strasbourg, 67087 Strasbourg, France \\ "University of Strasbourg Institute of Advanced Study, 67083 Strasbourg, France \\ ${ }^{\perp}$ Biomatériaux et Bioingénierie, Institut National de la Santé et de la Recherche Médicale, UMR-S 1121, 67087 Strasbourg, France \\ ${ }^{\#}$ Faculté de Chirurgie Dentaire, Fédération de Médecine Translationnelle de Strasbourg (FMTS), and Fédération des Matériaux et \\ Nanoscience d'Alsace (FMNA), Université de Strasbourg, 67000 Strasbourg, France

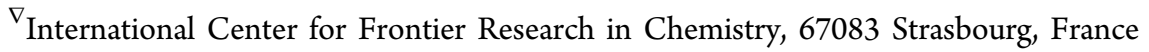

Supporting Information

\begin{abstract}
In medical diagnosis and environmental monitoring, enzymatic biosensors are widely applied because of their high sensitivity, potential selectivity, and their possibility of miniaturization/automation. Enzyme immobilization is a critical process in the development of this type of biosensors with the necessity to avoid the denaturation of the enzymes and ensuring their accessibility toward the analyte. Electrodeposition of macromolecules is increasingly considered to be the most suitable method for the design of biosensors. Being simple and attractive, it finely controls the immobilization of enzymes on electrode surfaces, usually by entrapment or adsorption, using an electrical stimulus. Performed manually, enzyme immobilization by cross-linking prevents enzyme leaching and was never done using an electrochemical stimulus. In this work, we present a mussel-inspired electro-cross-linking process using glucose oxidase (GOX) and a homobifunctionalized catechol ethylene oxide spacer as a cross-linker in the presence of ferrocene methanol (FC) acting as a mediator of the buildup. Performed in one pot, the process takes place in three steps: (i) electro-oxidation of FC, by the application of cyclic voltammetry, creating a gradient of ferrocenium $\left(\mathrm{FC}^{+}\right)$; (ii) oxidation of bis-catechol into a bis-quinone molecule by reaction with the electrogenerated $\mathrm{FC}^{+}$; and (iii) a chemical reaction of bis-quinone with free amino moieties of GOX through Michael addition and a Schiff's base condensation reaction. Employed for the design of a second-generation glucose biosensor using ferrocene methanol (FC) as a mediator, this new enzyme immobilization process presents several advantages. The cross-linked enzymatic film (i) is obtained in a one-pot process with nonmodified GOX, (ii) is strongly linked to the metallic electrode surface thanks to catechol moieties, and (iii) presents no leakage issues. The developed GOX/bis-catechol film shows a good response to glucose with a quite wide linear range from 1.0 to $12.5 \mathrm{mM}$ as well as a good sensitivity $\left(0.66 \mu \mathrm{A} / \mathrm{mM} \mathrm{cm}^{2}\right)$ and a high selectivity to glucose. These films would distinguish between healthy $(3.8$ and $6.5 \mathrm{mM})$ and hyperglycemic subjects $(>7 \mathrm{mM})$. Finally, we show that this electrocross-linking process allows the development of miniaturized biosensors through the functionalization of a single electrode out of a microelectrode array. Elegant and versatile, this electro-cross-linking process can also be used for the development of enzymatic biofuel cells.
\end{abstract}

KEYWORDS: glucose oxidase, electrodeposition, electropolymerization, catechol, dopamine, biochip, biofuel cell

\section{INTRODUCTION}

In recent years, an increasing interest in the integration of biomolecules onto electronic platforms was observed to create functional bioelectronic devices. One of the main challenges is the development of simple and low-cost analytical methods for biomarker detection. ${ }^{1,2}$ In biomedical applications, enzymes are commonly used as recognition elements because of their high specificity, selectivity, and catalyst efficiency under physiological conditions. $^{3-5}$ Thus, main research is focused on the development of enzymatic biosensors based on novel architectures incorporating enzymes able to transduce biorecognition as electric output signals. Enzymatic biosensors are

Received: March 23, 2018

Accepted: May 16, 2018

Published: May 25, 2018 

Bis-catechol

Glucose oxydase (GOX)<smiles>O=C(COCCOCCOCC(=O)NCCc1ccc(O)c(O)c1)NCCc1ccc(O)c(O)c1</smiles>
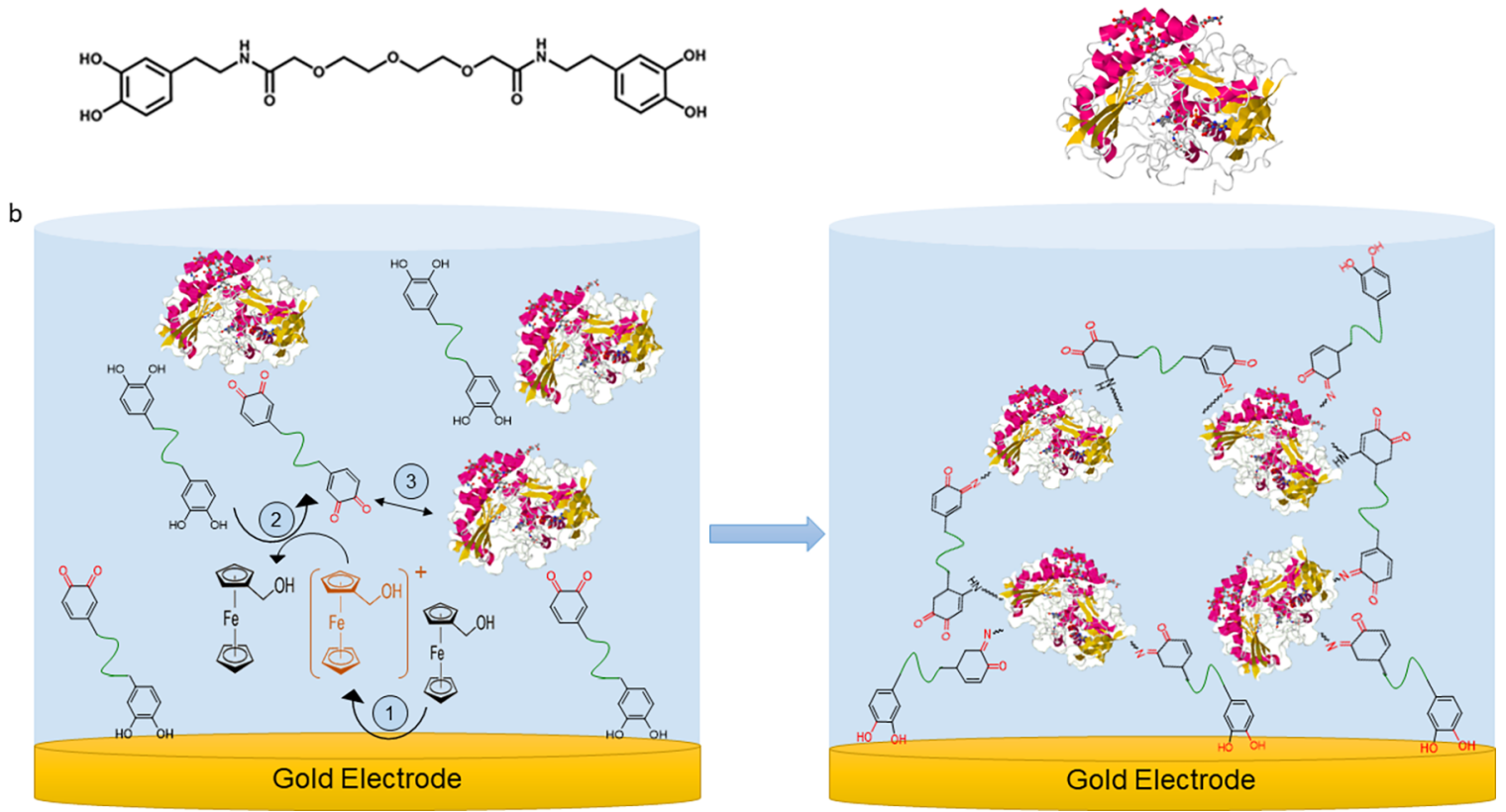

Figure 1. (a) Bis-catechol chemical formula and GOX quaternary structure (Protein Data Bank 1GAL JSmol Structure). (b) Principle of the one-pot mussel-inspired electrotriggered self-construction of enzymatic films based on three steps: (1) electro-oxidation of FC, creating a gradient of ferrocenium $\left(\mathrm{FC}^{+}\right)$, by the application of cyclic voltammetry; (2) oxidation of bis-catechol into bis-quinone molecules by reaction with $\mathrm{FC}^{+}$; and $(3)$ chemical reaction of bis-quinone with free amino moieties of GOX, through Michael addition and a Schiff's base condensation reaction.

a combination of an electrochemical probe (amperometric, potentiometric, or conductimetric) with a thin layer of an active immobilized enzyme. ${ }^{6,7}$ An extensive variety of redox enzymes, such as glucose oxidase $(\mathrm{GOX}){ }^{8}$ horseradish peroxidase (HRP), ${ }^{9}$ lactate oxidase, ${ }^{10}$ alcohol dehydrogenase, ${ }^{11}$ aldehyde dehydrogenase, ${ }^{12}$ and urease, ${ }^{13}$ have been used for the elaboration of glucose, $\mathrm{H}_{2} \mathrm{O}_{2}$, lactate, ethanol, aldehyde, and urea biosensors, respectively. Micro-enzyme-based biosensors have also been developed for short-term brain applications in animal models to monitor neurotransmitters, such as glutamate and choline, on the basis of immobilized glutamate or choline oxidase, respectively. ${ }^{14}$ GOX is the most common enzyme used owing to its importance in the detection of blood glucose ${ }^{15}$ and its effectiveness in the diagnostic analysis of diabetes. A representative case of success is the glucometer with test strips. However, the lack of accuracy of these systems is still a major concern. ${ }^{16,17}$ The low accuracy of the fabrication protocols and the high sensitivity of enzymes to the immobilization protocol or to the environmental factors can affect the reliability and reproducibility of glucose measurements. Enzyme immobilization is thus a critical process in biosensor development with the necessity to avoid its denaturation.

A variety of techniques have been implemented for the immobilization of enzymes onto solid surfaces, including adsorption, entrapment, covalent binding affinity, cross-linking, and affinity. ${ }^{18-22}$ Each immobilization method presents advantages and drawbacks. Well-studied, enzyme adsorption and entrapment present enzyme leakage issues. Covalent binding and cross-linking are known for enzyme stability but they decrease its activity after immobilization. Electrodeposition of macromolecules is increasingly considered to be the most suitable method for the creation of biosensors. ${ }^{23}$ This simple and attractive bottom-up approach finely controls the immobilization of enzymes on electrode surfaces, usually by entrapment or adsorption, using an electrical stimulus. Until now, three types of electrodeposition were developed to immobilize enzymes: (i) by changing the solubility of polyelectrolytes or enzymes, ${ }^{24-27}$ (ii) by polyelectrolytes selfassembly based on electrostatic/ionic interactions, ${ }^{28-31}$ and (iii) by electropolymerization of monomers. ${ }^{32,33}$ No electrocross-linking processes applied on enzymes were developed so far. Indeed, enzyme immobilization by cross-linking is usually performed manually by drop- or dip-coating of liquid enzyme preparations containing suitable cross-linkers, such as glutaraldehyde. Nonmanual procedures offer better reproducibility and better control of the immobilization process, especially for the development of miniaturized biosensors through the functionalization of single electrodes out of an assorted microelectrode array.

In the field of electrodeposition of macromolecules, we introduced a new concept based on electro-cross-linking between two polymers in one pot, named the morphogenic electrotriggered self-construction of films. A morphogen is a molecule or an ion generated locally to create a gradient and inducing a chemical reaction or interaction between two species. $\mathrm{Cu}(\mathrm{I})$ being the morphogen, our group used the Sharpless-Huisgen click reaction between azide and alkyne to obtain different polymeric films. ${ }^{34}$ Recently, we developed the electro-cross-linking of polyamines on the basis of musselinspired chemistry using a homobifunctional catechol ethylene oxide molecule, named bis-catechol, having the role of morphogen. ${ }^{35}$ Indeed, the exceptional ability of mussels to adhere on almost any type of surfaces is based on catechol biochemistry (i.e., hydrogen bonds, metal-ligand complexes, and covalent bond formation). In particular, after the oxidation of catechol to quinone, these new moieties react with nucleophilic groups, such as amines or thiols, through Michael addition and Schiff's base formation. ${ }^{36,37}$

In the present work, we describe mussel-inspired electrotriggered self-construction of enzymatic films for the develop- 
Scheme 1. Synthetic Route for the Preparation of Bis-Catechol in Two Steps

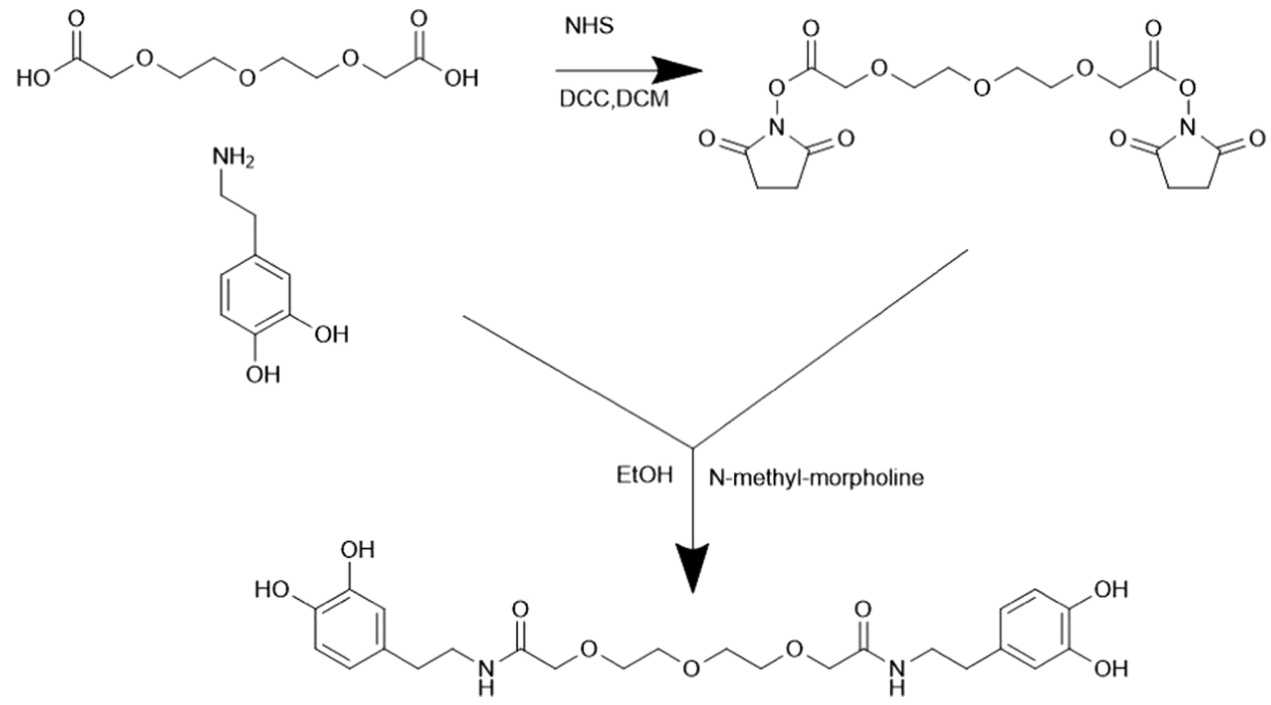

ment of a glucose biosensor by the cross-linking of GOX with bis-catechol on the surface of a gold electrode. An electrochemical mediator, ferrocene methanol (FC), was used as morphogen in the buildup solution. Performed in one pot with a bis-catechol/GOX/FC mixture solution, the process takes place in three steps: (i) electro-oxidation of FC, by the application of cyclic voltammetry (CV), creating a gradient of ferrocenium $\left(\mathrm{FC}^{+}\right)$; (ii) oxidation of bis-catechol to bis-quinone by reaction with the electrogenerated $\mathrm{FC}^{+}$; and (iii) chemical reaction of bis-quinone with free amino moieties of GOX through Michael addition and a Schiff's base condensation reaction (Figure 1). Efficiently immobilized with no-leaching out, GOX allows the electrochemical detection of glucose using $\mathrm{FC}$ as a free mediator in solution with a very good sensitivity and selectivity. Finally, the film buildup, occurring exclusively on the surface, can be performed on microelectrodes. This new synthesized biosensor can be classified as a second-generation glucose sensor. ${ }^{38}$

This new enzyme immobilization process presents several advantages: (i) it is a one-pot process; (ii) bis-catechol has a strong interaction with gold, allowing a strong stability of the immobilization; (iii) the enzyme is cross-linked, avoiding leakage issues; (iv) the obtained film is versatile, no chemical modification of the enzymes is needed; (v) being electrotriggered, it allows tunable and localized functionalization of electrodes; and (vi) it is composed of phenol moieties, which are known to be selective toward interferents (notably ascorbate, acetaminophen, and uric acid (UA)) of clinical significance in an amperometric assay. ${ }^{39,40}$

\section{EXPERIMENTAL SECTION}

Chemicals. Alkaline phosphatase (AP from bovine intestinal mucosa, CAS 9001-78-9), glucose oxidase (GOX from Aspergillus niger, CAS 9001-37-0), para-nitrophenyl phosphate liquid substrate (P7998, CAS 4264-83-9), salicylic acid (SA, $M=138.12 \mathrm{~g} / \mathrm{mol}$, CAS 69-72-7), ascorbic acid (AA, $M=176.12 \mathrm{~g} / \mathrm{mol}$, CAS 50-81-7), sodium nitrate $\left(\mathrm{NaNO}_{3}, M=84.99 \mathrm{~g} / \mathrm{mol}\right.$, CAS 7631-99-4), potassium hexacyanoferrate(II) $(M=422.41 \mathrm{~g} / \mathrm{mol}$, CAS $14459-95$ 1), $o$-dianisidine peroxidase $(M=244.29 \mathrm{~g} / \mathrm{mol}$, CAS 119-90-4), glucose $(M=180.16 \mathrm{~g} / \mathrm{mol}$, CAS 50-99-7), phosphate-buffered saline tablet (P4417), tris(hydroxymethyl)aminomethane (Tris, $M=121.14$ $\mathrm{g} / \mathrm{mol}$, CAS 77-86-1), and ferrocene methanol (FC, $M=216.06 \mathrm{~g} /$ mol, CAS 1273-86-5) were purchased from Sigma-Aldrich. Dopamine hydrochloride was purchased from Aldrich. 3,6,9-Trioxaundecandioic acid (TUDA) was purchased from Iris Biotech. All dried solvents were purchased from Acros Organics. Acetaminophen (AP, $M=151.17 \mathrm{~g} /$ mol, CAS 103-90-2) and uric acid (UA, $M=168.11 \mathrm{~g} / \mathrm{mol}$, CAS 6993-2) were purchased from Alfa Aesar. All chemicals were used as received and dissolved in aqueous solution using Milli- $Q$ water (resistivity of $18.2 \mathrm{M} \Omega \mathrm{cm}$ at $25{ }^{\circ} \mathrm{C}$ ). Phosphate buffer solution was prepared at $150 \mathrm{mM}$ phosphate, $2.06 \mathrm{M} \mathrm{NaCl}$, and $0.041 \mathrm{KCl}$ and adjusted at $\mathrm{pH} 7.4$.

Synthesis of Bis-Catechol. A two-step procedure was used to prepare bis-catechol from dopamine (CAS 62-31-7, Sigma) and 3,6,9trioxaundecandioic acid (TUDA, CAS 13887-98-4, Iris Biotech) (Scheme 1). ${ }^{1} \mathrm{H}$ NMR spectra were recorded on Bruker Advance DPX400 (400 MHz) spectrometers.

$\mathrm{N}, \mathrm{N}$-Succinimide Trioxaundecanediamide. 3,6,9-Trioxaundecandioic acid (TUDA, $0.99 \mathrm{~g}, 4.46 \mathrm{mmol}, 1.0$ equiv) was mixed with $5.31 \mathrm{~g}$ of molecular sieves in $\mathrm{CH}_{2} \mathrm{Cl}_{2}(20 \mathrm{~mL})$. N,N'-diciclohexilcarbodiimida ( $3.27 \mathrm{~g}, 16.19 \mathrm{mmol}, 3.6$ equiv) and $N$-hydroxysuccinimide ( $1.83 \mathrm{~g}, 15.91 \mathrm{mmol}, 3.6$ equiv) were added, and the mixture was stirred overnight. The mixture was filtered over celite. The volume of the solution was reduced under vacuum. Cold $\mathrm{Et}_{2} \mathrm{O}$ was then added to induce the precipitation of the product, and the mixture was stored in a cold medium overnight. After filtration, the precipitate was purified with flash chromatography (eluent dichloromethane), affording a solid white product $(0.28 \mathrm{~g}, 15 \%) .{ }^{1} \mathrm{H}$ NMR (MeOD- $d_{4}$, $400 \mathrm{MHz}) \delta 2.83(\mathrm{~s}, 8 \mathrm{H}) 3.79(\mathrm{~m}, 4 \mathrm{H}) 3.78(\mathrm{~m}, 4 \mathrm{H}) 4.52(\mathrm{~s}, 4 \mathrm{H})$.

Bis-Catechol. N,N-Succinimide trioxaundecanediamide $(0.28 \mathrm{~g}$, $0.67 \mathrm{mmol}, 1$ equiv) was dissolved in $5 \mathrm{~mL}$ of chloroform. Then, dopamine hydrochloride $(0.25 \mathrm{~g}, 1.34 \mathrm{mmol}, 2$ equiv), dissolved in 5 $\mathrm{mL}$ of EtOH, was added followed by $N$-methylmorpholine $(0.40 \mathrm{~mL}$, $3.35 \mathrm{mmol}, 5$ equiv), and the solution was stirred for $48 \mathrm{~h}$ at room temperature. The solvent was evaporated, and the residual solid was purified by flash chromatography eluting with $\mathrm{CH}_{2} \mathrm{Cl}_{2} / \mathrm{MeOH}$ (100:0 to $97: 3$ ), affording $0.25 \mathrm{~g}$ of the desired bis-catechol $(492.52 \mathrm{~g} / \mathrm{mol}$, $70 \%$ ). This product was found identical to the bis-catechol previously characterized in the literature. ${ }^{35}$

Synthesis of Rhodamine-Labeled GOX. A total of $100 \mathrm{mg}$ of the GOX was dissolved in $80 \mathrm{~mL}$ of a solution of $\mathrm{Na}_{2} \mathrm{CO}_{3}(0.1 \mathrm{M}, \mathrm{pH}$ 8.5 ) and stirred at $4{ }^{\circ} \mathrm{C}$ for $1 \mathrm{~h}$. A total of $340 \mu \mathrm{L}$ of rhodamine B isocyanate solution ( $1.5 \mathrm{mg}$ in $0.7 \mathrm{~mL}$ of dimethyl sulfoxide) was added to the GOX solution and remained stirred at $4{ }^{\circ} \mathrm{C}$ for $4 \mathrm{~h}$. Rhodamine-labeled GOX (GOX ${ }^{\text {Rho }}$ ) was purified by first dialyzing it (ZelluTrans dialysis membranes cutoff $12000-16000 \mathrm{~g} / \mathrm{mol}$ ) overnight in a solution of $0.25 \mathrm{M} \mathrm{NaCl}$ and then in pure water for several days.

Electrochemical Quartz Crystal Microbalance (EC-QCM) with Dissipation Monitoring. The Q-Sense E1 apparatus from Q-Sense 

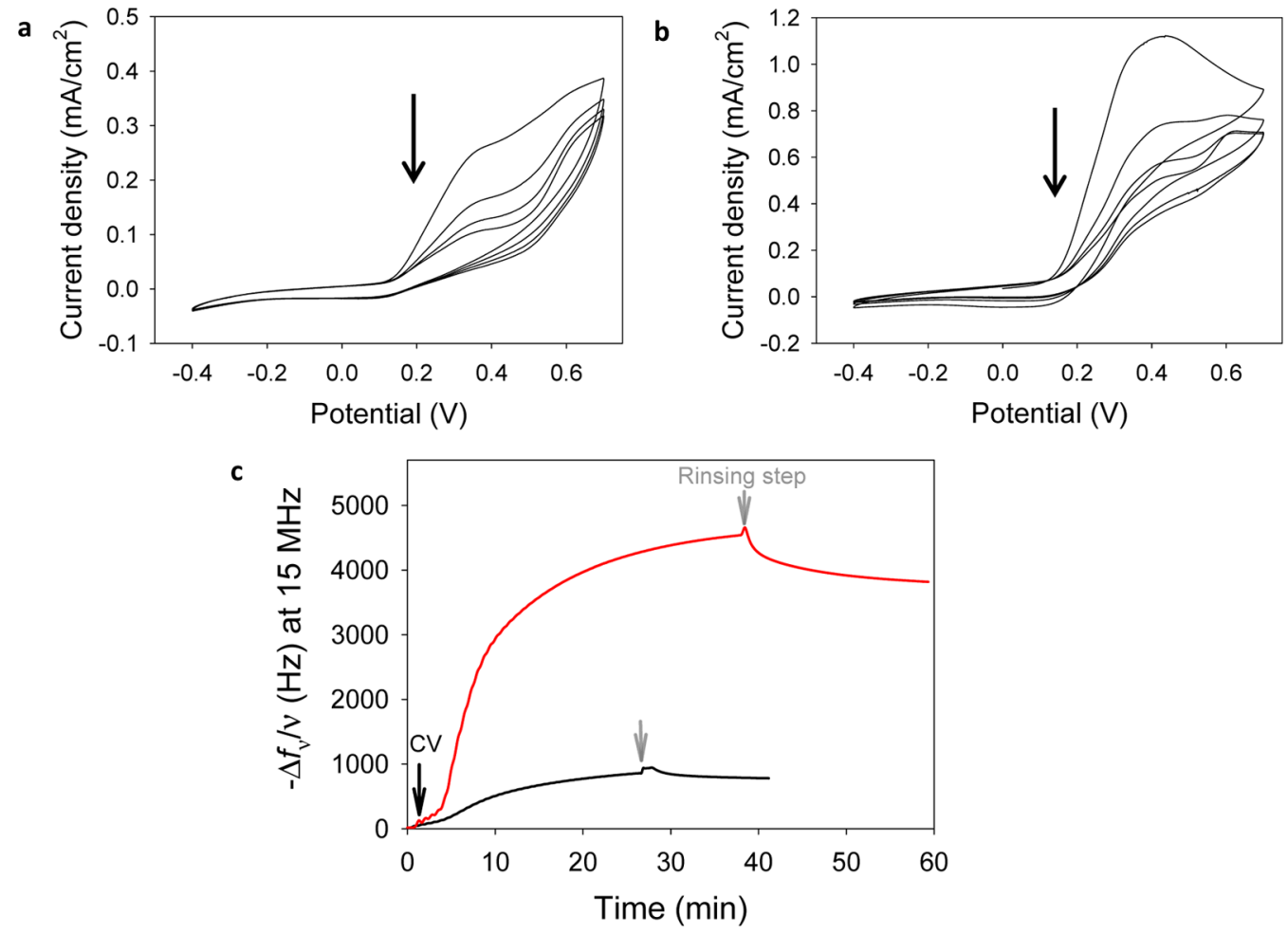

Figure 2. Cyclic voltammograms, performed at a scan rate of $0.05 \mathrm{~V} / \mathrm{s}$, of (a) bis-catechol $(6.1 \mathrm{mM})$ and (b) bis-catechol $(6.1 \mathrm{mM}) / \mathrm{FC}(0.5 \mathrm{mM})$ mixture solution, the black arrows indicating the evolution of the signal during the $\mathrm{CV}$ application, and (c) normalized frequency shift as a function of time of bis-catechol (black curve) and bis-catechol/FC mixture (red curve) solutions during the $\mathrm{CV}$ application $(\mathrm{range}-0.4-0.7 \mathrm{~V}$ vs $\mathrm{Ag} / \mathrm{AgCl}$, scan rate $0.05 \mathrm{~V} / \mathrm{s}$ ). The supporting electrolyte was phosphate buffer solution at $\mathrm{pH}$ 7.4.

$\mathrm{AB}$ (Gothenburg, Sweden) was used to perform the electrochemical quartz microbalance (EC-QCM) experiments by measuring the resonance frequency, $f_{\nu}$, and the dissipation factor, $D_{\nu}$, at $\nu=$ first, third, fifth, and seventh overtones, corresponding to $5,15,25$, and 35 $\mathrm{MHz}$ after the excitation of the quartz crystal at its fundamental frequency $(5 \mathrm{MHz})$. Only the third overtone at $15 \mathrm{MHz}$ is presented. The CHI660E apparatus ( $\mathrm{CH}$ instrument, Austin, TX) was coupled on the QCM-D apparatus with a three-electrode system to perform the electrochemical measurements. The gold-coated QCM sensor acted as a working electrode, a platinum electrode as a counter electrode on the top wall of the chamber, and a no-leak $\mathrm{Ag} / \mathrm{AgCl}$ electrode as a reference electrode fixed in the outlet flow channel. Before any buildup, the quality of the EC-QCM cell was tested by measuring the capacitive current in the presence of phosphate buffer and the faradic current in the presence of $1 \mathrm{mM}$ potassium hexacyanoferrate (II) prepared in phosphate buffer by applying five cycles between 0 and $0.7 \mathrm{~V}$ (vs $\mathrm{Ag} / \mathrm{AgCl}$ ) at $0.05 \mathrm{~V} / \mathrm{s}$.

Film Buildup Procedure. The enzyme/bis-catechol/FC mixture solution was prepared at $1 \mathrm{mg} / \mathrm{mL}$ GOX $(6.25 \mathrm{mM}), 3 \mathrm{mg} / \mathrm{mL}(6.1$ $\mathrm{mM}$ ) bis-catechol, and $0.5 \mathrm{mM} \mathrm{FC}$ in phosphate buffer at $\mathrm{pH}$ 7.4. To prevent the oxidation of bis-catechol, nitrogen was flushed in the prepared solutions. After the stabilization of the QCM signal with the buffer solution, $600 \mu \mathrm{L}$ of a mixture of bis-catechol, GOX, and FC was injected in the cell at a flow rate of $600 \mu \mathrm{L} / \mathrm{min}$ with a peristaltic pump. To trigger the electro-cross-linking of the enzyme, cyclic voltammetry was applied between 0.0 and $0.7 \mathrm{~V}$ (vs $\mathrm{Ag} / \mathrm{AgCl}$, scan rate $0.05 \mathrm{~V} / \mathrm{s}$ ). To stop the film buildup, a rinsing step with phosphate buffer was performed at a flow rate of $600 \mu \mathrm{L} / \mathrm{min}$ until the stabilization of the QCM signal. The coated QCM sensor was then kept in the cell for electrochemical characterization of the enzymatic activity or unmounted and stored into buffer solution for atomic force microscopy (AFM) or colorimetric characterizations.

Colorimetric Enzymatic Activity of GOX/Bis-Catechol Films. A microplate reader (Xenius XC, SAFAS, Monaco) was used to determine the catalytic activity of the enzymes within the films using the $o$-dianisidine assay. The films were disposed in a 24-well plate with $1 \mathrm{~mL}$ of a solution containing glucose $(1 \mathrm{mg} / \mathrm{mL}), \operatorname{HRP}(1 \mathrm{mg} / \mathrm{mL})$, and $o$-dianisidine $\left(10^{-3} \mathrm{M}\right)$ prepared in $150 \mathrm{mM} \mathrm{NaNO}_{3}-10 \mathrm{mM}$ Tris buffer at $\mathrm{pH}$ 8.0. GOX's activity was monitored using a second enzyme, HRP, which uses $\mathrm{H}_{2} \mathrm{O}_{2}$ produced by the GOX enzymatic reaction, in the presence of glucose, to react with $o$-dianisidine (colorless) to obtain oxidized $o$-dianisidine, which is brown. The reaction was followed at $440 \mathrm{~nm}$.

Electrochemical Enzymatic Activity of GOX/Bis-Catechol Films. All measurements were carried out on a CHI 660B electrochemical workstation ( $\mathrm{CH}$ Instruments). The same electrode setup that was used during the electrodeposition was used for the electrochemical performance study. The gold electrode was chosen as the working electrode. Cyclic voltammetry measurements were performed by injecting $600 \mu \mathrm{L}$ of solutions of different concentrations of glucose at $1 \mathrm{~mL} / \mathrm{min}$ in the absence and in the presence of a mediator (ferrocene methanol, FC). The chronoamperometric measurements of glucose were performed in Argon saturated solutions at a constant potential of $0.25 \mathrm{~V}(\mathrm{vs} \mathrm{Ag} / \mathrm{AgCl})$. The current density was calculated using a surface area of $0.8 \mathrm{~cm}^{2}$, which is the area of the QCM sensor exposed to the solution. ${ }^{41}$

Atomic Force Microscopy. The enzymatic films built on QCM crystals were characterized by AFM in contact mode and liquid state using Nanoscope IV from Veeco (Santa Barbara, CA). Deflection and height images were scanned at a fixed scan rate $(1 \mathrm{~Hz})$ with a resolution of $512 \times 512$ pixels using cantilevers (spring constant of $0.03 \mathrm{~N} / \mathrm{m}$ ) with silicon nitride tips (model MSCTAUHW, Veeco). To determine the film thickness by profilometric section analysis, several scratches were achieved using a plastic cone tip and imaged perpendicular to the fast scan axis. The film thickness is the minimal $z$ distance between the bare substrate and the surface of the film, which covers the whole substrate. Six areas were imaged to determine the mean and the standard deviation of the film thickness. The film roughness was determined by the RMS value given by AFM software (NanoScope software version 5.31r1, Digital Instruments, Veeco) on 3 $\times 3 \mu \mathrm{m}^{2}$ topographic images. 

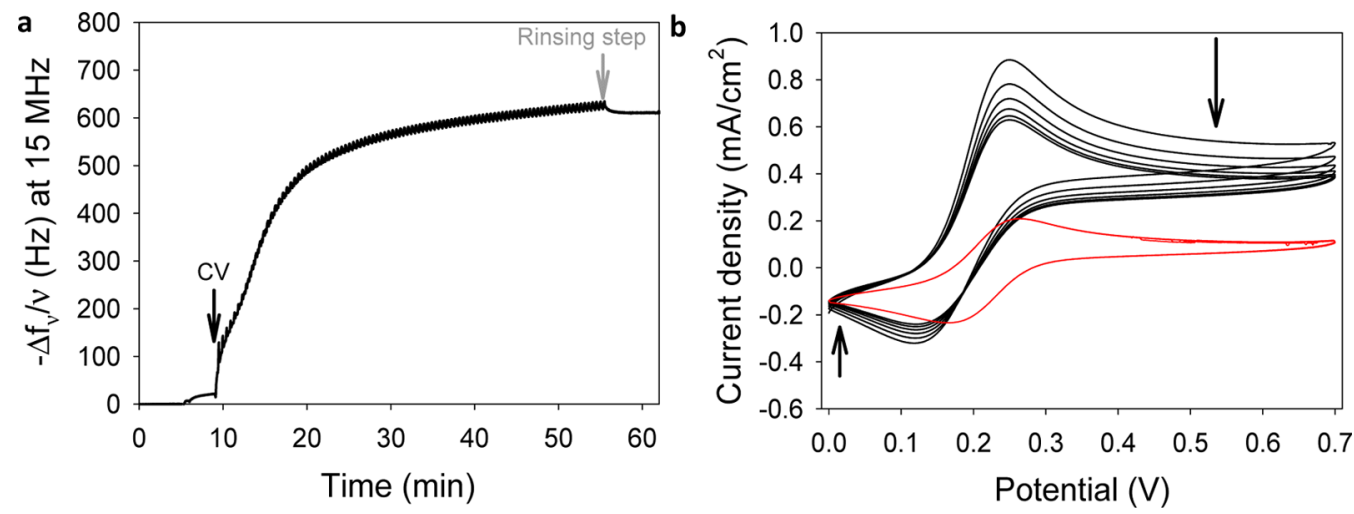

Figure 3. (a) Normalized frequency shift, measured by QCM, as a function of time during the self-construction of GOX/bis-catechol films by the application of $\mathrm{CV}(0.0-0.7 \mathrm{~V}$ vs $\mathrm{Ag} / \mathrm{AgCl}$, scan rate $0.05 \mathrm{~V} / \mathrm{s})$ for $45 \mathrm{~min}(100 \mathrm{cycles})$ using the bis-catechol $(6.25 \mathrm{mM}) / \mathrm{GOX}(6.1 \mathrm{mM}) / \mathrm{FC}(0.5$ $\mathrm{mM}$ ) mixture solution in phosphate buffer and (b) measured cyclic voltammograms, first five cycles (black curve) and last five cycles (red curve), the arrows indicating the evolution of the signal during self-construction.

Functionalization of Microelectrodes. Immersed in a biscatechol/GOX ${ }^{\text {Rho }} / \mathrm{FC}$ mixture (1 $\mathrm{mg} / \mathrm{mL}$ GOX, $3 \mathrm{mg} / \mathrm{mL}$ biscatechol, and $0.5 \mathrm{mM} \mathrm{FC}$ in a phosphate buffer at $\mathrm{pH} 7.4$ solution), the interdigitated array electrode (IDA ref: A-012125, Biologic) was addressed for $45 \mathrm{~min}$ through the application of a CV (between 0.0 and $0.7 \mathrm{~V}$ vs $\mathrm{Ag} / \mathrm{AgCl}$, scan rate $0.05 \mathrm{~V} / \mathrm{s}$ ) using a $\mathrm{CHI} 660 \mathrm{E}$ potentiostat/galvanostat in a three-electrode cell. The working electrode and the counter electrode were part of the IDA with a noleak $\mathrm{Ag} / \mathrm{AgCl}$ reference electrode. The coated IDA electrode was imaged using a SARFUS IMAGING HR station (Nanolane, Le Mans) in bright field and fluorescence mode.

\section{RESULTS AND DISCUSSION}

Bis-Catechol Synthesis and Electrochemical Characterization. Bis-catechol is a molecule displaying a catechol group at each end of a linear oligoethylene oxide chain. This hydrophilic molecule is stable and water soluble. Unlike our previous study, ${ }^{35}$ bis-catechol was prepared in two steps from dopamine and TUDA, both commercially available starting materials (Scheme 1). Briefly, TUDA was first modified by $N$ hydroxysuccinimide in $15 \%$ yield. Then, in the presence of two equivalents of dopamine, the bis-catechol was obtained in $70 \%$ yield. The overall yield of this synthesis was $10 \%$. We first investigated the electrochemical response of bis-catechol and bis-catechol/FC mixture solutions by cyclic voltammetry (CV) in phosphate buffer solution (Figure 2). For bis-catechol solution, the oxidation and reduction peaks were observed at 0.30 and $0.10 \mathrm{~V}$ (vs $\mathrm{Ag} / \mathrm{AgCl}$ ), respectively (Figure 2a), which is a good match with the literature. ${ }^{42,43}$ In the presence of FC, the redox peaks were slightly shifted to 0.35 and $0.05 \mathrm{~V}$ with higher values of intensity measured for the oxidation peak (Figure 2b). In both cases, the intensity of oxidation decreased dramatically with the number of cycles and the intensity of reduction was lower than that of the oxidation. This is the signature of an irreversible process. Simultaneously, an increase of the normalized frequency shift, measured by QCM and related to a mass deposition, was observed because of electrocross-linking of bis-catechol molecules (Figure 2c).

A higher increase of the normalized frequency shift was obtained for the bis-catechol/FC mixture in comparison to that for the bis-catechol solution, reaching a plateau after the rinsing step at $3800 \mathrm{~Hz}$ and $760 \mathrm{~Hz}$, respectively (Figure 2c). This result shows that FC molecules act as a mediator of a chemically irreversible process, favoring the oxidation of biscatechol to bis-quinone, which can further cross-link to deposit a film. This effect was already reported by Kim et al., who found that $\mathrm{FC}^{+}$(oxidized form of FC) can be reduced back to $\mathrm{FC}$ by the oxidation of grafted catecholic moieties. ${ }^{44}$ Applying a constant potential of $0.3 \mathrm{~V}$ (vs $\mathrm{Ag} / \mathrm{AgCl}$ ) to generate $\mathrm{FC}^{+}$, a small increase of the normalized frequency shift $(420 \mathrm{~Hz})$ was obtained after $50 \mathrm{~min}$ (Figure S1 in Supporting Information, SI). In the following, all the film buildups were performed in the presence of FC using CV between -0.4 and $0.7 \mathrm{~V}$ (vs Ag/ $\mathrm{AgCl}$ ) with a scan rate of $0.05 \mathrm{~V} / \mathrm{s}$.

GOX/Bis-Catechol Film Buildup Characterizations. Knowing that GOX has 15 on 30 accessible lysine residues for chemical modification, ${ }^{45}$ bis-catechol/GOX/FC mixture solutions were prepared in phosphate buffer at $\mathrm{pH} 7.4$ to obtain a catechol/amine ratio of 0.13 to favor the cross-linking of GOX with bis-catechol instead of bis-catechol self-cross-linking. Figure 3a shows the typical buildup of a GOX/bis-catechol film obtained by EC-QCM in the presence of FC.

A small increase of the normalized frequency was obtained at the injection of the buildup solution because of electrostatic adsorption of GOX and coordination bonding of bis-catechol with gold. A strong increase of the normalized frequency was obtained at the application of CV (range of $0.0-0.7$, scan rate of $0.05 \mathrm{~V} / \mathrm{s}$ ) followed by a slowdown, reaching $610 \mathrm{~Hz}$ after 45 min. The oxidation currents decreased dramatically with the number of cycles with a superimposition of the last five cycles (Figure $3 b$ ). The oxido-reduction signal was dominated by the FC signal. The oxidation peak was observed at $0.25 \mathrm{~V}$, and the reduction peak at $0.11 \mathrm{~V}$ shifted to $0.17 \mathrm{~V}$ at the end of the $\mathrm{CV}$ application. In comparison to that of the bis-catechol/FC mixture (Figure 2c), the kinetics of self-construction of the biscatechol/GOX/FC mixture was dramatically slower and the electrochemical signals were clearly different. This indicates that different buildup mechanisms were involved in the two cases.

The topography and thickness of the enzymatic films were determined by AFM in contact mode and liquid state. Figure 4 shows a homogenous morphology of the different films regardless to the deposition time. Scratching of the films was performed to determine their thicknesses. A nice scratched area was difficult to obtain because of the cross-linking of the enzyme and the strong interaction of bis-catechol with the gold surface. Thus, to ensure a reliable value, the mean thickness of the scratched film was determined by measuring it on at least six different areas. The films uniformly covered the whole 
a

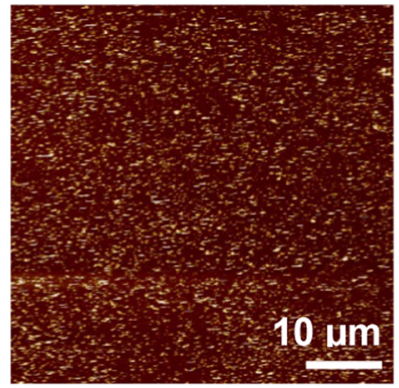

b

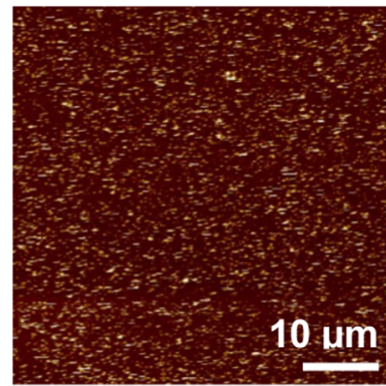

c

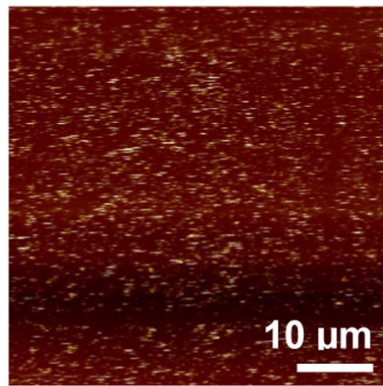

d

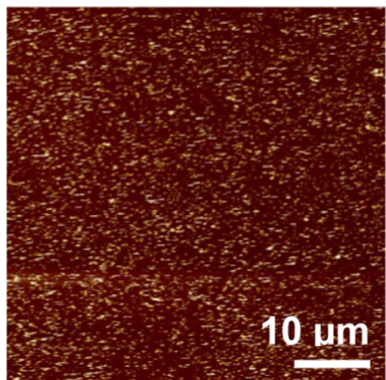

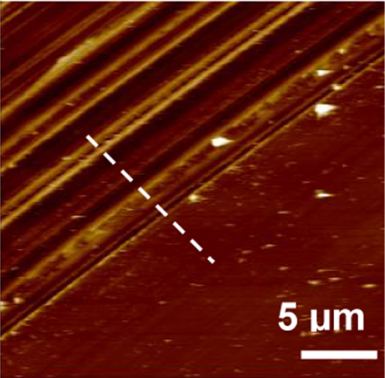
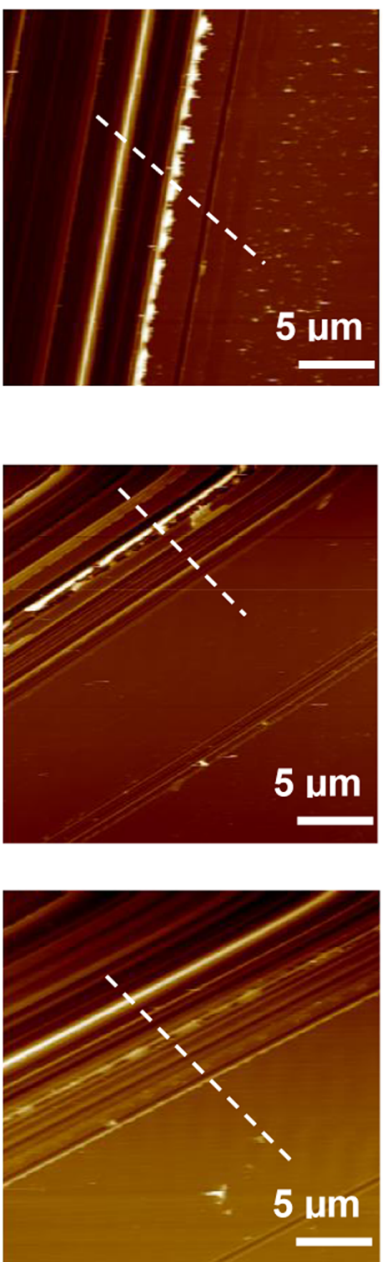
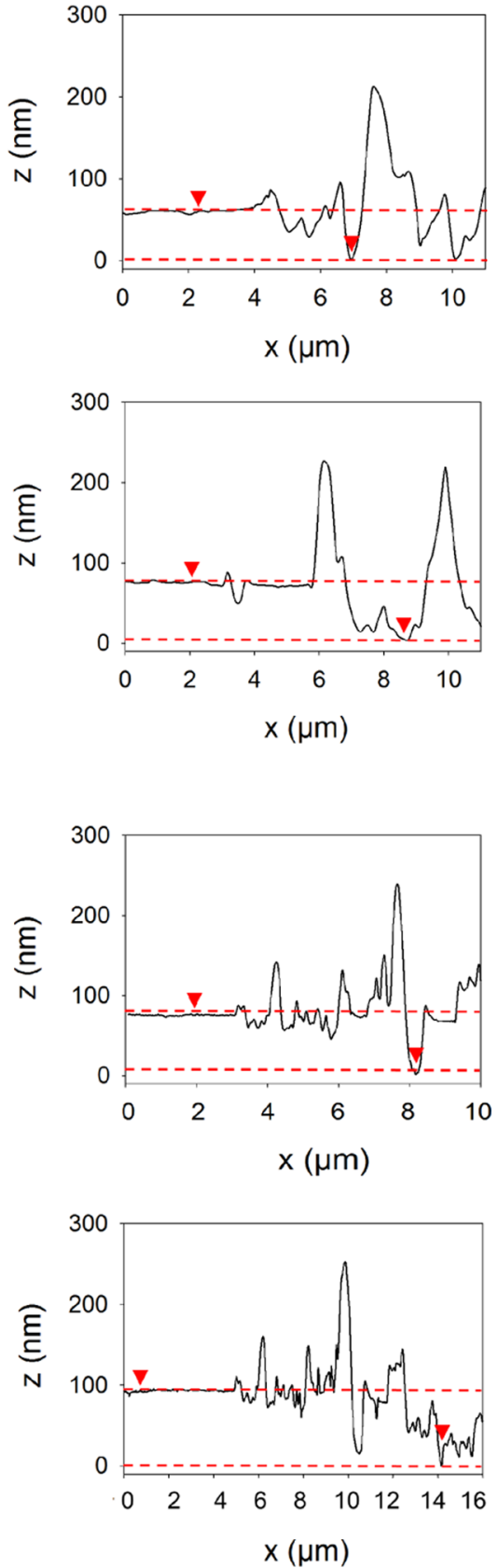

Figure 4. Typical topographic AFM images, obtained in contact mode and liquid state, before $\left(50 \times 50 \mu \mathrm{m}^{2}, z\right.$-scale $\left.=400 \mathrm{~nm}\right)$ and after scratching $\left(25 \times 25 \mu \mathrm{m}^{2}, z\right.$-scale $\left.=300 \mathrm{~nm}\right)$ with cross-sectional profiles of the GOX/bis-catechol film obtained after (a) 15 , (b) 30 , (c) 45 , and (d) $60 \mathrm{~min}$ of buildup using conditions of Figure 3. The white dotted bars represent the cross-sectional area.

substrate with a thickness varying from 55 to $100 \mathrm{~nm}$ when the film was built for 15-60 min, respectively (Figure 5). The film thickness increased as a function of the current time application, whereas the film roughness (determined on $3 \times$ $3 \mu \mathrm{m}^{2}$ images) remained constant at about $30 \mathrm{~nm}$ until $45 \mathrm{~min}$ of self-construction with a little increase at $50 \mathrm{~nm}$ for $60 \mathrm{~min}$ of buildup.

The enzymatic activity of the GOX/bis-catechol film was first investigated using a standard colorimetric test for different electrodeposition times going from 15 to $60 \mathrm{~min}$. The enzymatic analysis of the different films showed the best response for the self-constructed film at $30 \mathrm{~min}$ with no leaking of the GOX from the matrix because of the covalent cross- linking with the bis-catechol in the film (Figure S2 in Supporting Information, SI).

GOX/Bis-Catechol Film Biosensing Properties. To demonstrate the effective biofunctionalization of the electrode by the GOX/bis-catechol film, we examined the electrochemical biosensing capabilities of the deposited enzyme using standard enzyme-catalyzed glucose oxidation in the presence of FC. Indeed, as direct electron transfer of GOX could not be achieved because of the inaccessible enzymatic active site from the electrode, the FC mediator was used to enhance the electron transfer rate between GOX and the electrode. Diffusional electron mediators have been frequently employed to "shuttle" electrons between enzymes and anodes. ${ }^{46,47}$ These 


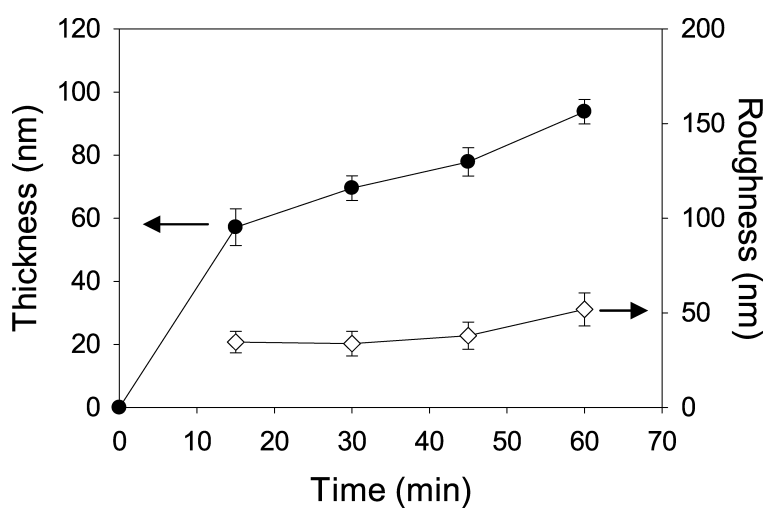

Figure 5. Thickness $(\bullet)$ and roughness (calculated on $3 \times 3 \mu \mathrm{m}^{2}$ AFM images) $(\diamond)$ of the self-constructed GOX/bis-catechol film, measured by AFM in contact mode and liquid state, as a function of self-construction time using conditions of Figure 3. The lines are drawn only to guide the eye.

mediators must possess an adequate solubility in both oxidized and reduced states for a rapid diffusion between the redox center of the enzyme and the electrode surface as well as a fast reaction with the reduced form of the enzyme. The sensing mechanism of glucose is based on the following equations

$$
\begin{aligned}
& \mathrm{FC} \rightarrow \mathrm{FC}^{+}+\mathrm{e}^{-} \text {(at electrode) } \\
& \mathrm{GOX}_{\mathrm{ox}}+\beta \text {-D-glucose } \rightarrow \mathrm{GOX}_{\text {red }}+\text { D-glucono- } \delta \text {-lactone } \\
& \mathrm{GOX}_{\text {red }}+2 \mathrm{FC}^{+} \rightarrow \mathrm{GOX}_{\mathrm{ox}}+2 \mathrm{H}^{+}+2 \mathrm{FC}
\end{aligned}
$$

In a typical electrochemistry test, the reduced form of the mediator, $\mathrm{FC}$, is oxidized into $\mathrm{FC}^{+}$by the application of an appropriate potential. The introduction of glucose triggers an increase of the anodic current caused by the regeneration of FC through the catalytic cycle depicted in Figure 6a. This increase of the anodic current contains information concerning the quantity of glucose. GOX/bis-catechol films were built for 30 min on gold-coated QCM crystals and further electrochemically characterized in EC-QCM cells by the injection of glucose solutions. On the basis of the recommendations of Liu et al, ${ }^{48}$ a $10 \mathrm{mM}$ phosphate buffer solution at $\mathrm{pH} 7.4$ was chosen as the optimal electrolyte to obtain maximum sensitivity of the biosensor. Figure $6 \mathrm{~b}$ shows the different cyclic voltammograms of the GOX/bis-catechol film in the absence and the presence of $0.5 \mathrm{mM} \mathrm{FC}$ at different concentrations of glucose, performed in an Ar-saturated environment. In the presence of FC, the oxidation and reduction peaks were observed at 0.27 and 0.16 $\mathrm{V}$, respectively, related to the redox behaviors of FC. No redox peaks were observed in a pure phosphate buffer or in the presence of $10 \mathrm{mM}$ glucose without a mediator. In the presence of FC, the addition of an increasing concentration of glucose led to a significant increase in the oxidation current and to a decrease in the reduction current of the redox couple of an FC mediator demonstrating a good bioelectrochemical catalytic activity of the GOX/bis-catechol film toward glucose oxidation. The potential of $0.25 \mathrm{~V}$ was selected as the optimal applied potential for further investigations.

Figure 7a shows the amperometric response of the GOX/biscatechol self-constructed film. Each fluid replacement led to an electrical current overshoot followed by a period of stabilization at a steady-state value. The overshoot happened in the transient period because of artifact noises or a local rise of glucose concentration around the electrode. The steady-state value increases with the solution's glucose concentrations. The functionality of GOX and the feasibility of the method for biosensing are confirmed by the increase in current upon addition of successive aliquots of glucose.

The calibration curve shows a linear range that extends from 1.0 to $12.5 \mathrm{mM}\left(R^{2}=0.993\right)$ on glucose concentration, which deviates from linearity at a higher concentration representing a typical characteristic of Michael-Menten kinetics (Figure $7 \mathrm{~b}$ inset). This system would distinguish between healthy (3.8 and $6.5 \mathrm{mM})$ and hyperglycemic subjects $(8.3-16.6 \mathrm{mM})$. The average sensitivity, calculated from the slope of the calibration curve, is $0.66 \mu \mathrm{A} / \mathrm{mM} \mathrm{cm}{ }^{2}$ with a detection capacity of the system at $0.6 \mathrm{mM}$ (limit of detection, at a signal-to-noise ratio of 3). The observed sensing sensitivity $\left(0.66 \mu \mathrm{A} / \mathrm{mM} \mathrm{cm}^{-2}\right)$ and linear range $(1-12.5 \mathrm{mM})$ of the GOX/bis-catechol biosensor are similar to those of cross-linked GOX biosensors based on human serum albumin/ferrocenyl-polymer $(0.33 \mu \mathrm{A} /$ $\mathrm{mM} \mathrm{cm}{ }^{-2}$ with a linear range of $\left.0.1-10 \mathrm{mM}\right)^{49}$ or on bovine serum albumin ${ }^{50}\left(0.74 \mu \mathrm{A} / \mathrm{mM} \mathrm{cm}^{-2}\right.$ with a linear range of 2.8-25 mM). In comparison to that of cross-linked GOX nanocomposite biosensors, based on $\mathrm{ZnO}$ nanotubes ${ }^{51}$ (21.7

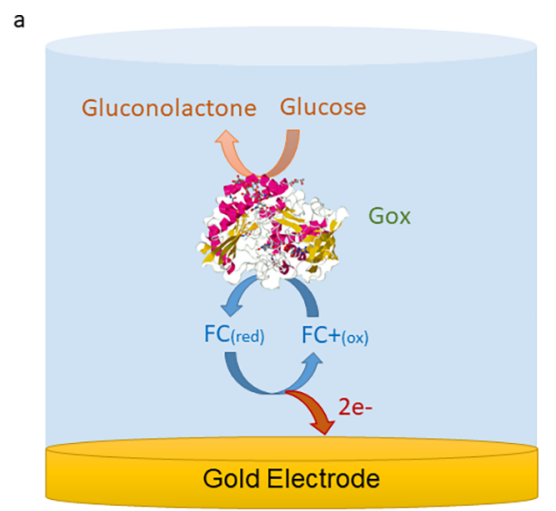

b

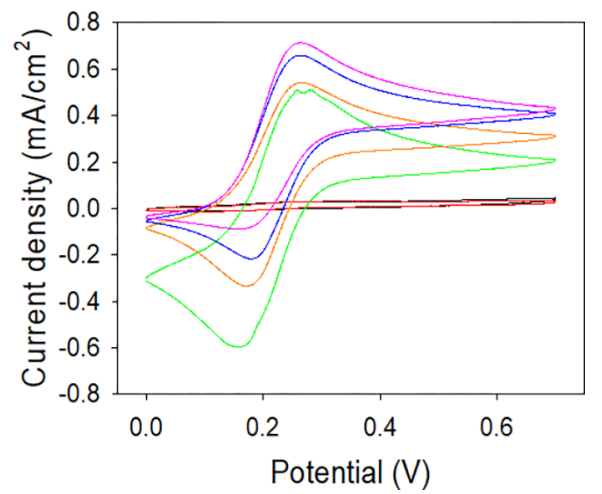

Figure 6. (a) Schematic representation of GOX catalytic reactions and oxido-reduction of FC in the self-constructed GOX/bis-catechol film allowing glucose sensing and (b) cyclic voltammograms, performed at a scan rate of $0.05 \mathrm{~V} / \mathrm{s}$, of self-constructed GOX/bis-catechol films in contact with a pure $10 \mathrm{mM}$ phosphate buffer saline (black curve), $10 \mathrm{mM}$ glucose (red curve), $0.5 \mathrm{mM} \mathrm{FC}$ (green curve), $10 \mathrm{mM}$ glucose and $0.5 \mathrm{mM}$ FC mixture (orange curve), $20 \mathrm{mM}$ glucose and $0.5 \mathrm{mM} \mathrm{FC}$ mixture (blue curve), and $40 \mathrm{mM}$ glucose and $0.5 \mathrm{mM} \mathrm{FC}$ (pink curve) mixture solutions, prepared in $10 \mathrm{mM}$ phosphate buffer saline and measured in an Ar-saturated environment. 
a

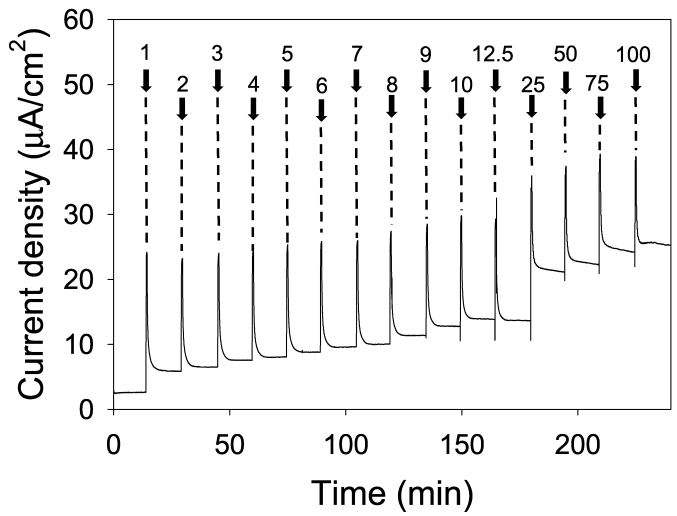

b

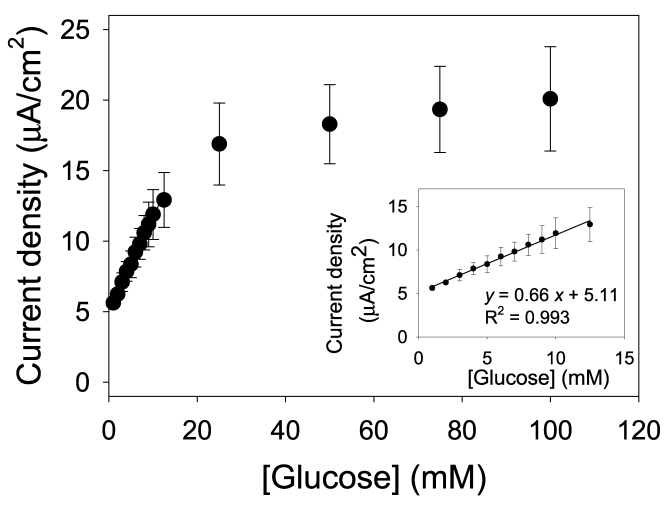

Figure 7. (a) Typical amperometric sensing evaluation and (b) average current density, with the inset showing the linear fit of average current density data, of the self-constructed GOX/bis-catechol film upon addition of $600 \mu \mathrm{L}$ of different concentrations of glucose (from 0.0 to $100 \mathrm{mM}$ ) in the presence of $0.5 \mathrm{mM} \mathrm{FC} \mathrm{during} \mathrm{the} \mathrm{application} \mathrm{of}+0.25 \mathrm{~V}$ vs $\mathrm{Ag} / \mathrm{AgCl}$. The average and error bars were evaluated on three independent experiments.
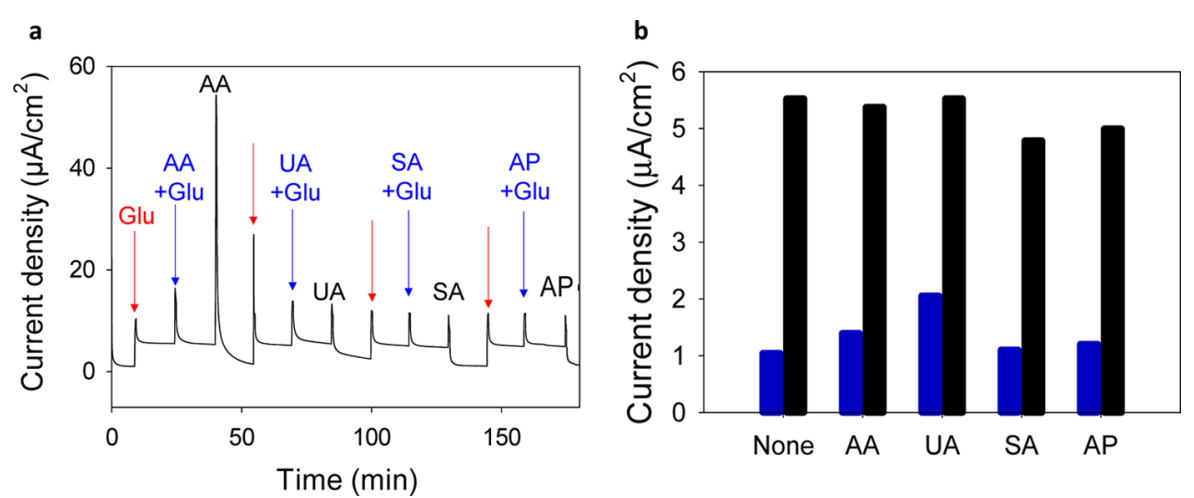

Figure 8. (a) Typical steady-state current response of the self-constructed GOX/bis-catechol film upon addition of $600 \mu \mathrm{L}$ of different interfering substances, ascorbic acid (AA), uric acid (UA), salicylic acid (SA), and acetaminophen (AP), in the absence and in the presence of $5 \mathrm{mM}$ glucose during the application of $+0.25 \mathrm{~V}$ vs $\mathrm{Ag} / \mathrm{AgCl}$ in the presence of $0.5 \mathrm{mM} \mathrm{FC}$. (b) Current density of the film in contact with a solution containing (black) $5 \mathrm{mM}$ glucose and (blue) $0 \mathrm{mM}$ glucose in the absence (None) and in the presence of interfering species (AA, UA, SA, and AP).

$\left.\mu \mathrm{A} / \mathrm{mM} \mathrm{cm}^{-2}\right)$, graphite composite electrodes $52(18.3 \mu \mathrm{A} / \mathrm{mM}$ $\left.\mathrm{cm}^{-2}\right)$, or boron-doped diamond electrodes ${ }^{53}(1.25 \mu \mathrm{A} / \mathrm{mM}$ $\left.\mathrm{cm}^{-2}\right)$, the sensitivity of the developed biosensor is lower. Indeed, nanocomposites are known to improve the sensitivity of biosensors. In contrast to the GOX/bis-catechol biosensor, all of these developed biosensors were obtained manually by drop-casting using a specific cross-linker. This method is not suitable for specific functionalization of a single electrode out of a microelectrode array.

The Michaelis-Menten constant $\left(K_{\mathrm{m}}^{\mathrm{app}}\right)$ was determined to evaluate the biological activity of the immobilized enzyme and is estimated using the following equation derived from the Lineweaver-Burk equation ${ }^{54}$

$$
\frac{1}{i_{\mathrm{ss}}}=\left(\frac{K_{\mathrm{m}}^{\mathrm{app}}}{i_{\max }}\right)\left(\frac{1}{C}\right)+\left(\frac{1}{i_{\max }}\right)
$$

where $i_{\mathrm{ss}}$ is the steady-state current after the addition of substrate, $i_{\max }$ is the maximum current measured under the saturated substrate condition, and $C$ is the bulk concentration of the substrate. A low $K_{\mathrm{m}}^{\mathrm{app}}$ indicates a high enzymatic activity of the immobilized GOX. ${ }^{55}$ The $K_{\mathrm{m}}^{\mathrm{app}}$ of the self-constructed GOX/bis-catechol film is about $6.3 \mathrm{mM}$, which is lower than the reported values of $10.36 \mathrm{mM}$ obtained for GOX/ polyaniline, $^{56} 19 \mathrm{mM}$ for $\mathrm{GOX} / \mathrm{ZnO}$ nanotubes, ${ }^{51}$ and 21.4 $\mathrm{mM}$ for $\mathrm{GOX} / \mathrm{CaCO}_{3}{ }^{57}$ biosensors. The above result further indicates that the electrodeposited films possess a high affinity to glucose with $I_{\max }=25 \mu \mathrm{A} / \mathrm{mM}$.

To prove the covalent immobilization of GOX, three sequential washes (for $5 \mathrm{~min}$ ) by the injection of $0.01 \%$ detergent Tween, prepared in a phosphate buffer, were performed during the chronoamperometry test. These washes were expected to remove any physically bound GOX. The current density measured before and after washes were similar (Figure S3 in SI). The selectivity of the GOX/bis-catechol functionalized biosensor was evaluated using common blood interfering substances, such as salicylic acid (SA, $0.75 \mathrm{mM}$ ), acetaminophen (AP, $0.35 \mathrm{mM}$ ), uric acid (UA, $0.5 \mathrm{mM}$ ), and ascorbic acid (AA, $0.15 \mathrm{mM}$ ), which could have a contribution to the amperometric signal because of their low redox potentials. Thus, the maximum common concentration of these molecules in blood (Medscape) was added to the buffer solution both in the absence and in the presence of $5 \mathrm{mM}$ glucose to measure the current response at $0.25 \mathrm{~V}$. There are no significant differences in the biosensor response because of the presence of these interfering species, suggesting an excellent anti-interference ability of the biosensor (Figure 8).

Because the electro-cross-linking of GOX using bis-catechol is localized near the electrode, we performed the functionalization of the interdigitated arrays (IDA) of electrodes using rhodamine-labeled GOX $\left(\mathrm{GOX}^{\mathrm{Rho}}\right)$ (Figure $\mathrm{S} 4$ in $\mathrm{SI}$ ) by 
applying CV on one of the two arrays for $45 \mathrm{~min}$. The spatial localization of $\mathrm{GOX}^{\mathrm{Rho}}$ on the addressed microelectrodes was checked by optical microscopy in fluorescence (Figure 9). The $\mathrm{GOX}^{\mathrm{Rho}} /$ bis-catechol film exhibited an excellent spatioselectivity because a high fluorescence was observed only on the addressed microelectrodes. a

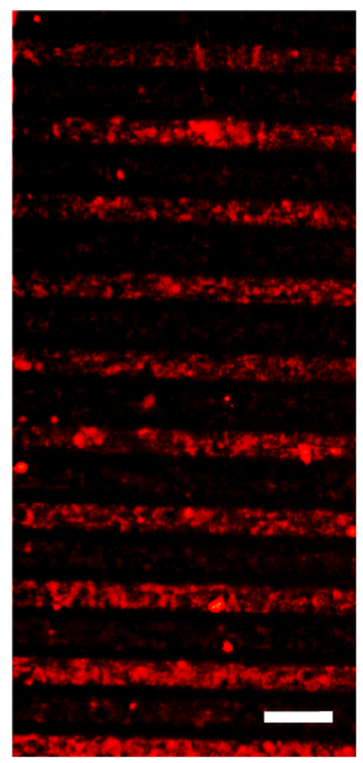

b

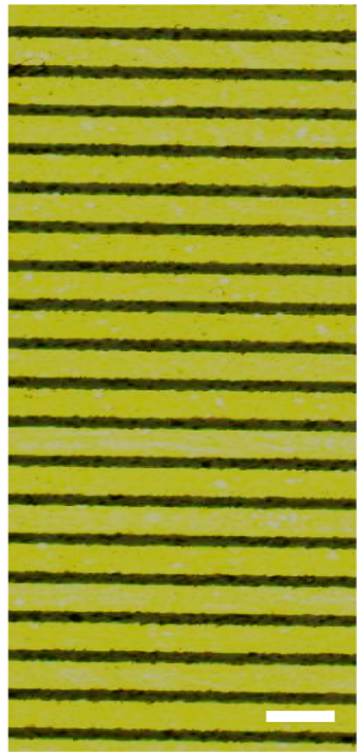

Figure 9. Optical microscope images of IDA electrodes (a) in fluorescence mode and (b) in bright field where one of the two arrays was addressed to self-constructed $\mathrm{GOX}^{\mathrm{Rho}} /$ bis-catechol films by the application of CV (range $0.0-0.7 \mathrm{~V}$ vs $\mathrm{Ag} / \mathrm{AgCl}$, scan rate $0.05 \mathrm{~V} / \mathrm{s}$ ) for $45 \mathrm{~min}$ using the bis-catechol/GOX/FC mixture solution in phosphate buffer in contact with IDA. The scale bar represents $25 \mu \mathrm{m}$.

\section{CONCLUSIONS}

We demonstrated the application of a mussel-inspired electrocross-linking process for the development of an electrochemical glucose biosensor of second generation, using bis-catechol as a cross-linker in the presence of GOX and FC as a mediator. This new enzyme immobilization process presents several advantages. Obtained in a one-pot process with a nonmodified enzyme, the cross-linked enzymatic film is strongly linked to the metallic electrode surface thanks to catechol moieties, presents no leakage issues, and can be deposited selectively on microelectrode arrays. The developed GOX/bis-catechol film shows a good response to glucose with a quite wide linear range from 1.0 to $12.5 \mathrm{mM}$ as well as a good sensitivity and a high selectivity to glucose. These films would distinguish between healthy (3.8 and $6.5 \mathrm{mM}$ ) and hyperglycemic subjects (>7 $\mathrm{mM}$ ). Compared to existing cross-linking methods of enzymes, the preparation of this new type of biosensor assembly is simple, fast, and reproducible, thus promising for the design of microbiosensors such as biochips. Moreover, this electro-crosslinking process can be also used to develop enzymatic biofuel cells.

\section{ASSOCIATED CONTENT}

\section{S Supporting Information}

The Supporting Information is available free of charge on the ACS Publications website at DOI: 10.1021/acsami.8b04764.
Evolution of the normalized frequency shift as a function of time of the bis-catechol/FC mixture during the application of a constant potential, evolution of the absorbance of $o$-dianisidine as a function of time in contact with GOX/bis-catechol films self-constructed at different times, typical steady-state current response of the self-constructed GOX/bis-catechol film before and after the Tween 20 detergent step, picture and schematic representation of interdigitated array (IDA) electrodes of $10 \mu \mathrm{m}$ width separated by $5 \mu \mathrm{m}$ (PDF)

\section{AUTHOR INFORMATION}

\section{Corresponding Author}

*E-mail: fouzia.boulmedais@ics-cnrs.unistra.fr. Phone: +33-388-41-41-60.

\section{ORCID $\odot$}

Pierre Schaaf: 0000-0001-7423-5492

Fouzia Boulmedais: 0000-0002-4934-9276

\section{Author Contributions}

The manuscript was written through contributions of all authors. All authors have given approval to the final version of the manuscript.

\section{Notes}

The authors declare no competing financial interest.

\section{ACKNOWLEDGMENTS}

J.E.-M. was supported by a post-doctoral fellowship from Labex "Chimie des Systèmes Complexes" (Labex CSC-PSC-13) and from Fondation de la Maison de la Chimie ("Retour congé maternité"). M.C. was supported by a Master fellowship from Idex and Erasmus. C.M. was supported by a fellowship from the "Ministère de la Recherche et de la Technologie". P.L. was supported by a post-doctoral fellowship from University of Strasbourg Institute for Advanced Study (USIAS). The authors gratefully acknowledge financial support from Agence Nationale de la Recherche (ANR JCJC Morphobuildup, ANR-13JS08-0003-01) and USIAS.

\section{REFERENCES}

(1) Bahadır, E. B.; Sezgintürk, M. K. Applications of Commercial Biosensors in Clinical, Food, Environmental, and Biothreat/biowarfare Analyses. Anal. Biochem. 2015, 478, 107-120 10.1016/ j.ab.2015.03.011.

(2) Vashist, S. K.; Luppa, P. B.; Yeo, L. Y.; Ozcan, A.; Luong, J. H. T. Emerging Technologies for Next-Generation Point-of-Care Testing. Trends Biotechnol. 2015, 33, 692-705.

(3) Ivnitski, D.; Abdel-Hamid, I.; Atanasov, P.; Wilkins, E. Biosensors for Detection of Pathogenic Bacteria. Biosens. Bioelectron. 1999, 14, 599-624.

(4) Wilson, G. S.; Gifford, R. Biosensors for Real-Time in Vivo Measurements. Biosens. Bioelectron. 2005, 20, 2388-2403.

(5) Ispas, C. R.; Crivat, G.; Andreescu, S. Recent Developments in Enzyme-Based Biosensors for Biomedical Analysis. Anal. Lett. 2012, $45,168-186$.

(6) Strike, D. J.; de Rooij, N. F.; Koudelka-Hep, M. Electrodeposition of Glucose-Oxidase for the Fabrication of Miniature Sensors. Sens. Actuators, B 1993, 13, 61-64.

(7) Sarma, A. K.; Vatsyayan, P.; Goswami, P.; Minteer, S. D. Recent Advances in Material Science for Developing Enzyme Electrodes. Biosens. Bioelectron. 2009, 24, 2313-2322.

(8) Bankar, S. B.; Bule, M. V.; Singhal, R. S.; Ananthanarayan, L. Glucose Oxidase - An Overview. Biotechnol. Adv. 2009, 27, 489-501.

(9) Liu, X.; Feng, H.; Zhang, J.; Zhao, R.; Liu, X.; Wong, D. K. Y. Hydrogen Peroxide Detection at a Horseradish Peroxidase Biosensor 
with a Au Nanoparticle-Dotted Titanate Nanotubelhydrophobic Ionic Liquid Scaffold. Biosens. Bioelectron. 2012, 32, 188-194.

(10) Rathee, K.; Dhull, V.; Dhull, R.; Singh, S. Biosensors Based on Electrochemical Lactate Detection: A Comprehensive Review. Biochem. Biophys. Rep. 2016, 5, 35-54.

(11) Çolak, Ö; Arslan, F. Amperometric Biosensing of Ethanol Based on Integration of Alcohol Dehydrogenase with a Pt/PPy-PVS/MB Electrode. Turk. J. Chem. 2015, 39, 84-95.

(12) Pariente, F.; Lorenzo, E.; Tobalina, F.; Abruna, H. D. Aldehyde Biosensor Based on the Determination of Nadh Enzymatically Generated by Aldehyde Dehydrogenase. Anal. Chem. 1995, 67, 3936-3944.

(13) Teke, M.; Sezgintürk, M. K.; Dinçkaya, E.; Telefoncu, A. A BioImprinted Urease Biosensor: Improved Thermal and Operational Stabilities. Talanta 2008, 74, 661-665.

(14) Weltin, A.; Kieninger, J.; Urban, G. A. Microfabricated, Amperometric, Enzyme-Based Biosensors for in Vivo Applications. Anal. Bioanal. Chem. 2016, 408, 4503-4521.

(15) Ferri, S.; Kojima, K.; Sode, K. Review of Glucose Oxidases and Glucose Dehydrogenases: A Bird's Eye View of Glucose Sensing Enzymes. J. Diabetes Sci. Technol. 2011, 5, 1068-1076.

(16) Huysal, K.; Budak, Y. U.; Demirci, H.; Önelge, M. Evaluation of CareSens POCT Devices for Glucose Testing in the Routine Hospital Setting. J. Clin. Diagn. Res. 2015, 9, BC04-BC07.

(17) Tonyushkina, K.; Nichols, J. H. Glucose Meters: A Review of Technical Challenges to Obtaining Accurate Results. J. Diabetes Sci. Technol. 2009, 3, 971-980.

(18) Gerard, M.; Chaubey, A.; Malhotra, B. D. Application of Conducting Polymers to Biosensors. Biosens. Bioelectron. 2002, 17, 345-359.

(19) Bakker, E.; Qin, Y. Electrochemical Sensors. Anal. Chem. 2006, 78, 3965-3984.

(20) Sassolas, A.; Blum, L. J.; Leca-Bouvier, B. D. Immobilization Strategies to Develop Enzymatic Biosensors. Biotechnol. Adv. 2012, 30, 489-511.

(21) Dominguez-Benetton, X.; Srikanth, S.; Satyawali, Y.; Vanbroekhoven, K.; Pant, D. Enzymatic Electrosynthesis: An Overview on the Progress in Enzyme- Electrodes for the Production of Electricity, Fuels and Chemicals. J. Microb. Biochem. Technol. 2013, S6, $7-27$.

(22) Ariga, K.; Ji, Q.; Mori, T.; Naito, M.; Yamauchi, Y.; Abe, H.; Hill, J. P. Enzyme Nanoarchitectonics: Organization and Device Application. Chem. Soc. Rev. 2013, 42, 6223-6345.

(23) Maerten, C.; Jierry, L.; Schaaf, P.; Boulmedais, F. Review of Electrochemically Triggered Macromolecular Film Buildup Processes and Their Biomedical Applications. ACS Appl. Mater. Interfaces 2017, 9, 28117-28138.

(24) Krylova, I. Painting by Electrodeposition on the Eve of the 21st Century. Prog. Org. Coat. 2001, 42, 119-131.

(25) Wu, L. Q.; Gadre, A. P.; Yi, H.; Kastantin, M. J.; Rubloff, G. W.; Bentley, W. E.; Payne, G. F.; Ghodssi, R. Voltage-Dependent Assembly of the Polysaccharide Chitosan onto an Electrode Surface. Langmuir 2002, 18, 8620-8625.

(26) Boccaccini, a. R; Keim, S.; Ma, R.; Li, Y.; Zhitomirsky, I. Electrophoretic Deposition of Biomaterials. J. R. Soc., Interface 2010, 7, S581-S613.

(27) Ammam, M. Electrochemical and Electrophoretic Deposition of Enzymes: Principles, Differences and Application in Miniaturized Biosensor and Biofuel Cell Electrodes. Biosens. Bioelectron. 2014, 58, $121-131$.

(28) Olsen, C.; Van Tassel, P. R. Polyelectrolyte Adsorption Kinetics under an Applied Electric Potential: Strongly versus Weakly Charged Polymers. J. Colloid Interface Sci. 2009, 329, 222-227.

(29) Koev, S. T.; Dykstra, P. H.; Luo, X.; Rubloff, G. W.; Bentley, W. E.; Payne, G. F.; Ghodssi, R. Chitosan: An Integrative Biomaterial for Lab-on-a-Chip Devices. Lab Chip 2010, 10, 3026-3042.

(30) Johnson, E. K.; Adams, D. J.; Cameron, P. J. Directed SelfAssembly of Dipeptides to Form Ultrathin Hydrogel Membranes. J. Am. Chem. Soc. 2010, 132, 5130-5136.
(31) Wong, I. Y.; Footer, M. J.; Melosh, N. A. Electronically Activated Actin Protein Polymerization and Alignment. J. Am. Chem. Soc. 2008, 130, 7908-7915.

(32) Ates, M. A Review Study of (Bio)sensor Systems Based on Conducting Polymers. Mater. Sci. Eng., C 2013, 33, 1853-1859.

(33) Erdőssy, J.; Horváth, V.; Yarman, A.; Scheller, F. W.; Gyurcsányi, R. E. Electrosynthesized Molecularly Imprinted Polymers for Protein Recognition. TrAC, Trends Anal. Chem. 2016, 79, 179190.

(34) Rydzek, G.; Jierry, L.; Parat, A.; Thomann, J. S.; Voegel, J. C.; Senger, B.; Hemmerlé, J.; Ponche, A.; Frisch, B.; Schaaf, P.; Boulmedais, F. Electrochemically Triggered Assembly of Films: A One-Pot Morphogen-Driven Buildup. Angew. Chem., Int. Ed. 2011, 50, 4374-4377.

(35) Maerten, C.; Garnier, T.; Lupattelli, P.; Chau, N. T. T.; Schaaf, P.; Jierry, L.; Boulmedais, F. Morphogen Electrochemically Triggered Self-Construction of Polymeric Films Based on Mussel-Inspired Chemistry. Langmuir 2015, 31, 13385-13393.

(36) Yang, J.; Cohen Stuart, M. A.; Kamperman, M. Jack of All Trades: Versatile Catechol Crosslinking Mechanisms. Chem. Soc. Rev. 2014, 43, 8271-8298.

(37) Deming, T. J. Mussel Byssus and Biomolecular Materials. Curr. Opin. Chem. Biol. 1999, 3, 100-105.

(38) Yoo, E.; Lee, S. Glucose Biosensors: An Overview of Use in Clinical Practice. Sensors 2010, 10, 4558-4576.

(39) Christie, I. M.; Vadgama, P.; Loyd, S. Modification of Electrode Surfaces with Oxidised Phenols to Confer Selectivity to Amperometric Biosensors for Glucose Determination. Anal. Chim. Acta 1993, 274, 191-199.

(40) Eddy, S.; Warriner, K.; Christie, I.; Ashworth, D.; Purkiss, C.; Vadgama, P. The Modification of Enzyme Electrode Properties with Non-Conducting Electropolymerised Films. Biosens. Bioelectron. 1995, $10,831-839$.

(41) Singh, K.; McArdle, T.; Sullivan, P. R.; Blanford, C. F. Sources of Activity Loss in the Fuel Cell Enzyme Bilirubin Oxidase. Energy Environ. Sci. 2013, 6, 2460-2464.

(42) Ojani, R.; Raoof, J. B.; Hosseinzadeh, R.; Alinezhad, A. Electrochemical Oxidation of Catechol in the Presence of Dimethyl Chloromalonate and Its Digital Simulation. Asian J. Chem. 2008, 20, 5863-5872.

(43) Kiani, A.; Raoof, J. B.; Nematollahi, D.; Ojani, R. Electrochemical Study of Catechol in the Presence of Dibuthylamine and Diethylamine in Aqueous Media: Part 1. Electrochemical Investigation. Electroanalysis 2005, 17, 1755-1760.

(44) Kim, E.; Liu, Y.; Shi, X. W.; Yang, X.; Bentley, W. E.; Payne, G. F. Biomimetic Approach to Confer Redox Activity to Thin Chitosan Films. Adv. Funct. Mater. 2010, 20, 2683-2694.

(45) Hosseinkhani, S.; Ranjbar, B.; Naderi-Manesh, H.; NematGorgani, M. Chemical Modification of Glucose Oxidase: Possible Formation of Molten Globule-like Intermediate Structure. FEBS Lett. 2004, 561, 213-216.

(46) Katz, E.; Shipway, A. N.; Willner, I. Mediated Electron-Transfer between Redox-Enzymes and Electrode Supports. Encycl. Electrochem. 2002, 9, 559-626.

(47) Katz, E.; Shipway, A. N.; Willner, I. The Electrochemical and Photochemical Activation of Redox Enzymes. Electron Transfer in Chemistry Volume 4: Heterogeneous Systems, Solid State Systems, Gas Phase Systems Section 1: Catalysis of Electron Transfer; Wiley, 2001; Vol. 4, pp 127-201.

(48) Liu, Y.; Wang, M.; Zhao, F.; Xu, Z.; Dong, S. The Direct Electron Transfer of Glucose Oxidase and Glucose Biosensor Based on Carbon Nanotubes/chitosan Matrix. Biosens. Bioelectron. 2005, 21, 984-988.

(49) Kamin, R. A.; Wilson, G. S. Rotating Ring-Disk Enzyme Electrode for Biocatalysis Kinetic Studies and Characterization of the Immobilized Enzyme Layer. Anal. Chem. 1980, 52, 1198-1205.

(50) Al-Sagur, H.; Komathi, S.; Karakaş, H.; Atilla, D.; Gürek, A. G.; Basova, T.; Farmilo, N.; Hassan, A. K. A Glucose Biosensor Based on 
Novel Lutetium Bis-Phthalocyanine Incorporated Silica-Polyaniline Conducting Nanobeads. Biosens. Bioelectron. 2018, 102, 637-645.

(51) Kong, T.; Chen, Y.; Ye, Y.; Zhang, K.; Wang, Z.; Wang, X. An Amperometric Glucose Biosensor Based on the Immobilization of Glucose Oxidase on the ZnO Nanotubes. Sens. Actuators, B 2009, 138, 344-350.

(52) Zhao, Z. X.; Qiao, M. Q.; Yin, F.; Shao, B.; Wu, B. Y.; Wang, Y. Y.; Wang, X. S.; Qin, X.; Li, S.; Yu, L.; Chen, Q. Amperometric Glucose Biosensor Based on Self-Assembly Hydrophobin with High Efficiency of Enzyme Utilization. Biosens. Bioelectron. 2007, 22, 30213027.

(53) Dai, H.; Zhong, Y.; Wu, X.; Hu, R.; Wang, L.; Zhang, Y.; Fan, G.; Hu, X.; Li, J.; Yang, Z. Synthesis of Perovskite-Type $\mathrm{SrTiO}_{3}$ Nanoparticles for Sensitive Electrochemical Biosensing Applications. J. Electroanal. Chem. 2018, 810, 95-99.

(54) Campbell, A. S.; Islam, M. F.; Russell, A. J. Intramolecular Electron Transfer through Poly-Ferrocenyl Glucose Oxidase Conjugates to Carbon Electrodes: 1. Sensor Sensitivity, Selectivity and Longevity. Electrochim. Acta 2017, 248, 578-584.

(55) Yonemori, Y.; Takahashi, E.; Ren, H.; Hayashi, T.; Endo, H. Biosensor System for Continuous Glucose Monitoring in Fish. Anal. Chim. Acta 2009, 633, 90-96.

(56) Barsan, M. M.; Brett, C. M. A. A New Modified Conducting Carbon Composite Electrode as Sensor for Ascorbate and Biosensor for Glucose. Bioelectrochemistry 2009, 76, 135-140.

(57) Su, L.; Qiu, X.; Guo, L.; Zhang, F.; Tung, C. Amperometric Glucose Sensor Based on Enzyme-Modified Boron-Doped Diamond Electrode by Cross-Linking Method. Sens. Actuators, B 2004, 99, 499504. 